Estudios Constitucionales, Año 13, № 2, 2015, pp. 351-390

ISSN 07180195

Centro de Estudios Constitucionales de Chile Universidad de Talca

"Problemas de la representación proporcional en el sistema electoral

brasileño actual y sus reflejos en una eventual crisis de los partidos políticos"

Ana Claudia Santano - Claudia Maria Barbosa - Katya Kozicki

\title{
PROBLEMAS DE LA REPRESENTACIÓN PROPORCIONAL EN EL SISTEMA ELECTORAL BRASILEÑO ACTUAL Y SUS REFLEJOS EN UNA EVENTUAL CRISIS DE LOS PARTIDOS POLÍTICOS*
}

\author{
PROBLEMS OF PROPORTIONAL REPRESENTATION IN THE CURRENT \\ BRAZILIAN ELECTORAL SYSTEM AND THEIR REFLECTION ON AN EVENTUAL \\ CRISIS OF POLITICAL PARTIES
}

\begin{abstract}
Ana Claudia Santano ${ }^{1}$
Pontifícia Universidade Católica do Paraná (Brasil)

anaclaudiasantano@yahoo.com.br

Cláudia Maria Barbosa ${ }^{2}$

Pontifícia Universidade Católica do Paraná (Brasil)

claudia.mr.barbosa@gmail.com

KatYa KozicKi ${ }^{3}$

Pontifícia Universidade Católica do Paraná (Brasil)

katyakozicki@gmail.com
\end{abstract}

RESUMEN: Mucho se afirma sobre una eventual crisis de los partidos que afecta su legitimación en la democracia moderna, pero poco o nada se ha investigado sobre su veracidad. Es cierto que el principio representativo ya no goza más de tanto prestigio en un escenario de fuerte complejidad social, como el de

\footnotetext{
* Trabajo recibido el 2 de abril de 2015 y aprobado el 26 de agosto de 2015.

1 Doctora y Maestra en Ciencias Jurídicas y Políticas por la Universidad de Salamanca, España; actualmente se encuentra en estancia posdoctoral en la Pontificia Universidad Católica de Paraná, Brasil. Investigadora en el Núcleo de Investigaciones Constitucionales de la Universidad Federal de Paraná, Brasil.

2 Profesora titular del Programa de Posgrado en Derecho de la Pontificia Universidad Católica de Paraná, Brasil. Doctora y maestra en Derecho por la Universidad Federal de Santa Catarina, Brasil. Postdoctora por la York University, Canadá.

3 Profesora de los programas de grado y posgrado en Derecho de la Pontifica Universidad Católica de Paraná, Brasil, y de la Universidad Federal de Paraná, Brasil. Maestra en Filosofía de Derecho y del Estado por la Universidad Federal de Santa Catarina, Brasil (1993). Visiting researcher associate, Centre for the Study of Democracy, University of Westminster, Londres (1998-1999). Doctora en Derecho, Política y Sociedade por la Universidad Federal de Santa Catarina, Brasil (2000). Visiting research scholar, Benjamin N. Cardozo School of Law, Nueva York (2012-2013). Becaria de productividad en investigación del CNPq, Brasil.
} 
Brasil. Sin embargo, tampoco se puede ignorar el hecho de que el sistema electoral colabora sobremanera para estos resultados negativos. Ante esto, por medio de una revisión de la literatura, en una primera parte será analizado el perfil dogmático de la representación politica y sus desequilibrios, adentrando en la supuesta crisis de los partidos. Luego se expone el derecho de participación política en el marco de la democracia participativa y deliberativa. Posteriormente se inicia el análisis de la función de los partidos de ser los canales de participación política por medio del sistema electoral brasileño, verificando las barreras producidas por él que impiden la concreción de dicha función. Como conclusión, se tiene que son tamañas las distorsiones provocadas por el sistema electoral vigente que, en realidad, no son los partidos los únicos culpables por el abalo de la legitimidad democrática en Brasil, sino también el procedimiento de selección de representantes, que urge por reformas.

ABSTRACT: Much is said about a possible crisis of political parties which affects their legitimacy in modern democracy, but almost nothing has been studied in order to prove its veracity. It is true that the principle of representativeness has not so much prestige as it was used to have due to the strong social complexity, as the Brazilian one. However, one cannot ignore the fact that the electoral system works greatly for these negative results. Given this, through a literature review, in the first part will be analyzed the dogmatic profile of political representation and its imbalances, moving into the alleged political parties crisis. After, the right to participate in politics is exposed through the participatory and deliberative democracy framework. Continuing, it shows the analysis of the role of the parties to be the channels of participation in politics and the Brazilian electoral system, starting by checking the barriers produced by it, blocking the realization of this function. In conclusion, one can strongly verify there are so direct distortions caused by the current electoral system that, in fact, the political parties are not the only guilty for this negative result of democratic legitimacy in Brazil, but also the method of selecting representatives, which claims for immediate reform.

PALABRAS CLAVE: Sistema electoral; Brasil; Estado; democracia; desarrollo.

KEY WORDS: Electoral system; Brazil; State; democracy; development.

\section{UNA APROXIMACIÓN DOGMÁTICA A LA REPRESENTACIÓN POLÍTICA}

La representación es una función propia del Estado, una representación institucional. Sus problemas dan inicio cuando el crecimiento de la complejidad de la sociedad provoca la ampliación de la base electoral con el aporte de cada vez más demandas, lo que dificulta notoriamente la relación representante-representado ${ }^{4}$.

Si se atribuye al Parlamento la condición de institución que reúne y debate los conflictos sociales existentes, es necesario que haya un procedimiento electoral que posibilite la conversión de votos habidos en escaños, eligiendo los componentes de dicha institución a partir de su fuerza social. Es sabido que no hay fórmulas electorales perfectas, capaces de reflejar exactamente la cantidad de votos en los electos, principalmente considerando las grandes poblaciones que son comunes en el mundo contemporáneo. Asimismo, las fórmulas electorales

4 BARBERA (2008), p. 859. 
provocan -en mayor o menor grado- una distorsión resultado entre el número de electores y el número de sus representantes por diversas razones, sea por cuestiones de gobernabilidad, sea de pura reducción de la complejidad social5. De esta forma, si dicha conversión de la fuerza social en parlamentaria se ve alterada, dicha institución tendrá dificultades para cumplir sus funciones ${ }^{6}$, ya que parte de los intereses sociales habrán quedado marginados o subrepresentados ${ }^{7}$. Un gobierno democrático se caracteriza fundamentalmente por su continua aptitud para responder a las preferencias de sus ciudadanos, sin establecer diferencias políticas entre ellos. Así, la democracia es un sistema político que se caracteriza por su disposición a satisfacer a todos los ciudadanos de manera completa o casi $^{8}$; pero, por otro lado, la democracia también supone un gobierno de la mayoría, con base en el principio "una persona, un voto", contándose un voto como realmente uno9. Para Ronald Dworkin, la democracia no se identifica con el principio mayoritario, sino que le atribuye otro sentido, relacionándolo con el trato de todos los ciudadanos con igual consideración y respeto, a partir de la estructura, de la composición y de las prácticas de las instituciones políticas. Esta igual consideración y respeto es lo que da legitimidad a las decisiones colectivas tomadas en el Parlamento por el principio mayoritario, o por medio del Poder Judicial en el ejercicio de la llamada dificultad "contramayoritaria", y no por el apoyo de la mayoría de los ciudadanos o de los representantes. A todo ello Dworkin llama de democracia constitucional ${ }^{10}$.

En la concepción individualista de representación, cuantos más individuos haya en la sociedad, más se pierde de vista quién está siendo efectivamente representado. En este contexto, el elector particular se vuelve menos individuo, porque si vota identificándose con una clase o un grupo, no es porque el voto es particular que él puede ser tenido como algo singular. Cuanto más individuos existan para

\footnotetext{
5 TAVARES (1995), p. 193. Muchas veces dichas distorsiones, aunque justificadas por razones que quizá pudieran servir de soporte, acaban por favorecer a los partidos mayoritarios. Véase Holgado GonzÁleZ (2006), pp. 2692-2693.

6 En la concepción de Kelsen, "la función representativa es ejercida por un parlamento electo por el pueblo, y las funciones administrativas y judiciarias igualmente elegidos por un electorado". Así, "un gobierno solo es 'representativo' porque y en la medida en la que sus funcionarios, durante la ocupación del poder, reflejan la voluntad del electorado y son responsables para con ese”. KELSEN (1992), p. 283.

7 Castillo (1978), p. 153.

8 DAHL (2002), p. 13.

9 Reynoso (2002), p. 55.

10 Dworkin (1996), p. 17.
} 
ser representados en las instituciones, el propio término "representatividad" va perdiendo su primer sentido ante la realidad ${ }^{11}$.

Considerando estos razonamientos, parece evidenciada una relación directa entre la representación y la participación política, incluso porque, en realidad, la representación es una manera de participación y de involucrar a los ciudadanos en el Estado y en el proceso de toma de decisiones, no siendo un mero ejercicio de una función entre la sociedad y la esfera estatal ${ }^{12}$. Por otro lado, no se ignora el hecho de que la representación política esté bastante condicionada a la estructura legislativa (unicameral o bicameral), y a la forma de distribución de escaños entre los distritos, es decir, o de manera territorial (como dispone el federalismo) o de manera demográfica (que suele ser señalado como el que corresponde más al principio democrático) ${ }^{13}$.

Además, se sabe que la participación política también involucra a los partidos políticos. Es un hecho que dichas organizaciones generan una dualidad de percepciones. Parece ser que, si hay política, hay partidos, pues su existencia es necesaria para cualquier régimen democrático. Sin embargo, también están directamente vinculados al lado más "nebuloso" de las instituciones públicas, ostentando quizá la posición más "incómoda” dentro de la arena pública.

La evolución de los partidos se ha acompasado al propio desarrollo de las sociedades democráticas occidentales. Desde el siglo XIX los partidos políticos fueron incorporándose paulatinamente a la escena pública, sirviendo de cauce de ciertas demandas sociales, o de igual forma reivindicando derechos del ciudadano antes inexistentes. En los orígenes del moderno Estado Constitucional tan solo existían, como es sabido, lo que se ha denominado partidos de cuadros. Lo que pasó en las etapas posteriores no fue más que la consecuencia directa de la transformación de las estructuras sociales a partir de la gradual extensión del sufragio y de la agudización de las luchas sociales y el propio cambio que naturalmente alcanza a la sociedad, lo que también abrió el camino para la evolución de los partidos para el modelo de masas y el catch all, seguido por el que se denomina partidos cartel ${ }^{14}$.

En realidad, la existencia y la continuidad de los partidos siempre estuvieron lejos de ser una unanimidad. Las políticas y los gobiernos pueden ser coordinados

11 SARTORI (2005), pp. 271-272.

12 Bastida Freijedo (1987), p. 210; Presno Linera (2000), pp. 27-28.

13 Reynoso (2002), p. 57.

14 López Guerra (1977), p. 107; Kirchheimer (1980), p. 331; Panebianco (1982), pp. 480 y ss.; Offe (1988), p. 65; MAIR (1997), pp. 101-102. 
por dichas organizaciones, aunque esto no los vuelve instituciones en su sentido más genuino ${ }^{15}$. Esto es evidente en muchos países donde existe una permanente desconfianza en contra de los partidos, aunque ellos ejerzan las funciones también consideradas como públicas, como puede ser Estados Unidos que, desde el siglo XVIII, se nutre de un sentimiento antipartidista que buscó paulatinamente limitar sus actividades ${ }^{16}$. Esto explicaría en parte, por ejemplo, que las campañas electorales estadounidenses estén más centradas en los candidatos que en las organizaciones partidistas ${ }^{17}$. En el caso brasileño, la situación presenta algunas especificidades, pero no resulta ser muy distinta: la dictadura implantada en el país entre 1964 y 1985 prohibió a los partidos como una forma de contener la oposición y dificultar la actuación de los movimientos sociales que actuaban políticamente a través de estos, lo que causó su debilitamiento. El pluripartidismo solamente regresó con la Constitución de 1988, aunque en este momento el problema de la representación ya era algo distinto, porque la sociedad ya había encontrado maneras de movilización externas a la vía partidista, llevándolos a una crisis de legitimidad que solo aumenta desde entonces. Esta situación de contrariedad hacia los partidos también restó muy consolidada por medio de las protestas promovidas por ciudadanos de diversas partes del país a finales de junio de 2013, poniendo en jaque la propia legitimidad de las instituciones públicas en donde las organizaciones partidistas tienen una actuación preponderante.

\section{2. ¿LA CRISIS EXISTENTE ES DE LOS PARTIDOS, DE LA REPRESENTATIVIDAD O DE LOS DOS?}

Es considerablemente perceptible la existencia de una cierta crisis de representatividad, que puede que resulte en una crisis de participación política y que por lógica alcanza a los partidos, lo que no significa exactamente que exista una crisis de dichas organizaciones, por más que ellos sean los actores principales de la democracia y que muy probablemente hayan colaborado al fomento de esta insatisfacción.

15 En este sentido, cf. Colomer (2001), p. 16, como un concepto adecuado para lo que se propone en este artículo.

16 Siendo esta desconfianza, incluso, el origen de la atribución de un valor mayor a los candidatos personalmente, y no a los partidos. Cf. WARE (1996), p. 1.

17 Ryden (1996), pp. 145-147. El autor cita el caso de Williams v. Rhodes, una candidatura independiente que fue negada por la ley electoral de Ohio para competir en las elecciones de 1968, ganando dicho derecho después del fallo favorable. 
El estudio de los partidos políticos y del desarrollo de la política realizado hace cuarenta años por La Palombara y Weiner decía que la institucionalización y expansión de los partidos eran unos elementos esenciales para las políticas democráticas, y que afirmar que el desarrollo de dichas organizaciones era un fundamento para la evolución de la política era correcto en aquel período. Sin embargo, con el pasar de los años, y principalmente en América Latina, dicho desarrollo no se concretó de la manera como se pensaba, generando partidos débiles y despertando un cuestionamiento de su importancia ${ }^{18}$. Ya en Europa occidental, lo que se produjo fue la erosión de la movilización de los partidos políticos, antes compuesta por la identificación partidista y la confianza en dichas organizaciones, elementos estos que también están siendo importantemente afectados ${ }^{19}$.

En Brasil, el artículo 17 de la Constitución Federal de 1988 deja claro que los partidos políticos son instrumentos relevantes en la función y manifestación de la voluntad popular, al seleccionar y permitir canales de comunicación entre la sociedad y el poder político. Dicha función es la que principalmente se ha asignado a los partidos, ya que deben agrupar la voluntad popular para intentar transformarla en la directriz del gobierno, del Estado, requiriendo para ello una voluntad permanente de concurrir a las elecciones y también adquiriendo los partidos una posición privilegiada en la contienda electoral ${ }^{20}$.

Ahora bien, obviamente los partidos no son los únicos responsables de la conformación de dicha voluntad popular ${ }^{21}$, aunque en Brasil ellos tengan el monopolio de las candidaturas, según el art. $14, \$ 3^{\circ}$, V de la Magna Carta y que sean, así, el único camino legal para acceder al Parlamento. Con esto, se puede afirmar que su posición en la realización de esta función es privilegiada, es decir, que entre los actores existentes para ejercer dicha función de concurrencia, formación y manifestación de la voluntad popular, sin duda las organizaciones partidistas son los protagonistas ${ }^{22}$.

18 La Palombara (2007), pp. 141-154.

19 Cf. Dalton (2007), p. 139.

20 Cf. García Guerrero (1990), pp. 151-153.

21 Con una visión negativa del tema, Offe afirma que a partir del momento en que la voluntad popular es traducida a través de los partidos, esta deja de ser popular para ser una estructura formada para la concurrencia política. OfFe (1988), p. 62.

22 Grimm (1996), p. 389. Complementando la idea, Álvarez Conde entiende que los partidos convierten la voluntad popular en voluntad estatal a través de las elecciones como "agencias de socialización política". Álvarez Conde (1991), p. 112. 
Como regulación del art. 17 de la Constitución Federal de 1988, la ley No 9.096/95, ya en su artículo primero destaca que los partidos políticos se destinan a asegurar el sistema representativo y a defender los derechos fundamentales. Respecto al sistema representativo, se puede considerar que esto es una cualidad de los partidos, y que su consecuencia es la expresión del pluralismo político. Se nota a la vez una remisión indirecta a la voluntad popular y a la formación y manifestación de esta. Teniendo en mente que la expresión de la voluntad popular incluye a un amplio grupo de ciudadanos, se podría fijar un parámetro para su conceptualización para fines de este trabajo, que correspondería a las necesidades y exigencias que se originan en el seno de una sociedad y que no pueden ser traducidas solamente a partir del voto. Por lo tanto, no sería erróneo entender que la voluntad popular no se expresa únicamente en el momento de emisión del sufragio.

En este punto, González Encinar hace una interesante diferenciación entre los términos "pueblo" y "votantes", "democracia" y "elecciones" y "representación" y "democracia". Con relación a la primera dicotomía, el autor afirma que el pueblo no tiene solo una voluntad, sino diversas voluntades, ya que se trata de un colectivo y forman parte de dichos intereses los prejuicios, ignorancias y la apatía política que afecta a estas "voluntades". Por ello no se puede decir que elecciones son expresión de la voluntad popular, porque dicha voluntad ni siquiera es apta para actuar políticamente ${ }^{23}$. Posteriormente, la voluntad del Estado democrático es la popular, porque pasadas las elecciones, los partidos elegidos conformarán el Estado para formar su "voluntad", y en estas instituciones del Estado hay voluntad popular porque de estas emanan las instituciones, es decir, los poderes del Estado vienen del pueblo y crean las leyes a partir de esta voluntad preexistente ${ }^{24}$. Así, el Estado expresa su voluntad popular porque la expresa democráticamente, de acuerdo con el procedimiento democrático ${ }^{25}$. Debido a todo ello, el autor entiende que la formación de la voluntad popular es algo permanente en la sociedad y en

23 De Vega entiende que las críticas que los partidos sufren de que son organizaciones desintegradoras y que poseen solamente intenciones particularistas son, en realidad, críticas a la democracia, y no solo a los partidos. Sería este el caso de la supuesta ignorancia de la voluntad popular por parte de los partidos pasadas las elecciones. DE VeGA (1977), pp. 14-15.

24 Junto a ello, Grimm entiende que los partidos políticos no se limitan a la función de la formación de la voluntad popular, sino también la del Estado, a través de sus parlamentarios, que no solo representan a la sociedad, sino que también están vinculados a los propios partidos y que también dirigen el Estado. De este modo, la formación de la voluntad popular sería permanente, teniendo en las elecciones su culminación. Grimm (1996), pp. 396-397.

25 Maximizando esta afirmación, el autor entiende que todas las personas que ejercen cargos y oficios públicos representan la voluntad popular y no solo los cargos elegidos directamente. 
el Estado, siendo las elecciones una manifestación de este proceso. No hay pueblo y Estado en este orden, sino un proceso que se traduce en una relación dialéctica entre ellos, y que, involucrados individuos y colectividad, permite a los partidos políticos destacarse en esta mediación ${ }^{26}$.

Partiendo de este punto, los partidos serían un vehículo para la formación y comunicación de dicha voluntad popular y de la socialización política ya que, en la concurrencia existente, también se organiza políticamente la sociedad, estableciendo conexiones con el Estado. Además, también seleccionan una élite política responsable de conducir en las organizaciones representativas los programas electorales presentados para el electorado. También protagonizan el proceso electoral y ejercen el papel de gobernantes o de oposición, dentro de la dinámica del Estado. Además, los partidos serían así los responsables tanto del control del propio gobierno, como también de la actualización de los programas políticos, adaptándolos a los cambios y a las nuevas demandas venidas desde la sociedad 27.

El problema de la voluntad popular surge de la gran complejidad de voluntades individuales de una sociedad. Siendo los partidos políticos responsables principales de la formación y manifestación de la voluntad popular, se convierten en un instrumento de reducción de dicha complejidad ${ }^{28}$. Con todo, para que esta reducción esté en consonancia con el concepto de Estado democrático, los partidos deben saber cómo canalizar este proceso y constituirse realmente en medios de expresión de toda esta pluralidad que pueda existir ${ }^{29}$. Partiendo de estos supuestos, Navarro Méndez entiende que esta es la principal función de los partidos, pero que únicamente se cumple cuando, en una sociedad compleja, los partidos logran seleccionar demandas y, a través de medios democráticos,

26 González Encinar (1992), pp. 20-24. Dentro de esta perspectiva, De Esteban y López Guerra entienden que la función de los partidos de formación y manifestación de la voluntad popular solamente será ejercida efectivamente cuando los electores estén informados de los programas de los partidos y cuestiones políticas. Si así no fuera, dicha función no se realizaría y solamente se harán a los ciudadanos preguntas que ellos ignoran. De Esteban y López Guerra (1983), pp. 76-77.

27 Torres del Moral (1992), p. 470.

28 En este sentido, resulta obligada la cita de los trabajos de LuHMANn (1980); (1983); (1985).

29 Fernández-Miranda Campoamor y Fernández-Miranda Campoamor (2003), pp. 43-44. En este punto los autores complementan la idea con su opinión de que, aunque los partidos políticos no pueden ser considerados como órganos del Estado, se les reconoce un status constitucional que conlleva una protección especial, además de conferirles muchos beneficios, como tener acceso a las fuentes de financiación pública, que tienen como uno de sus objetivos justamente garantizar la igualdad de oportunidades en la participación política. 
hacer que dichas demandas sean escuchadas, sin eliminar las diferencias y el derecho de crítica ${ }^{30}$.

Tangencialmente a la perspectiva descrita e interconectada con la complejidad de la sociedad y la capacidad de los partidos de filtrarla, y si la voluntad popular se hace escuchar a través del resultado del sufragio, ella también reside en los órganos representativos elegidos. Partiendo de este punto, los partidos que no concurren a la formación y expresión de la voluntad popular, y cuya actividad extraparlamentaria o cotidiana se limita a la de meras asociaciones políticas, suponen actividades no garantizadas o irrelevantes. Dentro de este panorama, lo cierto es que existe un debate doctrinal sobre si el cumplimiento formal y material de estas funciones determina la condición de partido y, consecuentemente, el disfrute de los beneficios y de la protección concedida por la ley. Hay autores, como Jiménez Campo, que entienden que los partidos que no cumplen de manera formal y material la función de formación y manifestación de la voluntad popular no deben ser considerados partidos, sino simplemente asociaciones políticas ${ }^{31}$. Hay países que incluso adoptaron esta interpretación, como es el caso de Alemania ${ }^{32}$ y España ${ }^{33}$, lo que reafirmaría la posición de los autores que entienden que las elecciones son el momento de la verdadera expresión de la voluntad popular, y en consecuencia es el momento en que los partidos políticos cumplen con la función de formación y expresión de la voluntad popular ${ }^{34}$.

Capturar la voluntad popular, defenderla en el Parlamento y realizarla por medio de acción política, sin embargo, no es una operación fácil, aun cuando el

30 Navarro Méndez (1999), p. 233.

31 Jiménez CAmpo (1992), p. 217.

32 Según dispone el artículo 2.2 de la Ley sobre los Partidos Políticos de Alemania (Parteiengesetz - PartG): "Una asociación pierde su posición jurídica como partido si durante seis años no participa con sus propias propuestas electorales en unas elecciones para el Bundestag o para un Landtag”. Traducción extraída del sitio web del Instituto Göethe [fecha de consulta 29 septiembre de 2014].

33 En 2011 la Ley Orgánica del Régimen Electoral General (Ley 5/1985 de 19 de junio) sufrió una reforma significativa, agregando un apartado $3^{\circ}$ en el art. 169, que establece requisitos para la presentación de candidaturas tanto de partidos, federaciones o coaliciones que no lograron escaños en las elecciones anteriores, como para las agrupaciones de electores. La obligatoriedad del cumplimiento de dichos requisitos -basados en la presentación de firmas de por lo menos el $0,1 \%$ de electores listados en el censo electoral de la circunscripción donde se presenta la candidatura.

34 Cf. Navarro Méndez (1999), p. 236, y Esparza Oroz (1994), p. 50, en la que el autor afirma que no es la mera existencia del partido lo que le confiere derechos, pero sí es necesaria su concurrencia a la manifestación de la voluntad popular, controlando la funcionalidad del gobierno y la eficacia de los poderes públicos, algo que también legitimaría la imposición de barreras electorales. 
voto es universal y que tengan el mismo valor, como es el caso brasileño. Esto porque la aparente equidad en la representación de voluntades, garantizada por el sistema "one man, one vote", desconsidera elementos importantes en la formación y exteriorización de esta propia voluntad, como la asimetría de información, el conocimiento y la capacidad de evaluación de causas y consecuencias de las elecciones hechas. Por esto, se hace necesario tener en cuenta la posición de autores como Lucas Verdú, que entienden que dejar de formar la voluntad popular no puede generar sanciones a los partidos políticos porque abarcar todas las demandas y aspectos sociales existentes es algo imposible. Así, el cumplimiento obligatorio y material escapa a la capacidad de los partidos políticos y, por lo tanto, estos no deben perder parte de sus prerrogativas jurídicas ${ }^{35}$. Además, si se considera como verdadera la idea inicialmente expuesta de que la voluntad popular no se forma o se manifiesta solamente en el momento del sufragio, o que para ejercer esta función concedida por la Constitución sus titulares deberán cumplir requisitos previos, quizá cabe pensar si no se trata de una medida indebidamente impuesta a los partidos que acaba por obstaculizar el cumplimiento de dicha función, o si las medidas ahora exigidas en realidad reflejan en cierta forma una crisis en esta función de representatividad generada por el fallido ejercicio de las atribuciones partidistas $^{36}$.

Debido a ello, la última afirmación puede fácilmente volverse una pregunta: ¿Están los partidos sufriendo actualmente una crisis en esta función de representatividad generada por el fallido ejercicio de las atribuciones partidistas?

La representación política es uno de los principios de un Estado Democrático y se realiza a partir de la elección de los representantes por los ciudadanos -en una clara manifestación de la voluntad popular, dichos representantes expresarán las demandas sociales por las cuales fueron elegidos, aunque representarán a toda la sociedad ${ }^{37}$. Así, la representación política ${ }^{38}$ puede ser entendida como

35 LuCAS Verdú (1984), pp. 585-587.

36 En este sentido, son muy aclaradoras las lecciones de Bоввіо (1986), pp. 21-36.

37 Quiere decir que los representantes elegidos representan a toda la colectividad, aunque exista el deseo por parte de la Constitución de que dicho representante dé efecto durante el mandato a las demandas expresadas por sus votantes. Bastida Freijedo (1987), p. 212. También, cf. Barbera (2008), p. 854.

38 Por la amplitud del presente trabajo, no es posible tratar todos los aspectos que involucran la representación política, principalmente si acaso consideran su origen y desarrollo filosófico. Así, cf. para una exposición del perfil filosófico de la representación política, DUVERGER (1970), pp. 116-120; LeIBHOLZ (1971), pp. 13-49; PitKin (1985), pp. 233-239, y UGo Resigno (1995), pp. 543-560, en el que el autor compara este tipo de representación con la representación jurídica. Por fin, cf. Vega García (1997), 
un procedimiento en que una determinada clase política es elegida para conducir las demandas de la sociedad a los órganos e instituciones estatales, con el fin de involucrarlos en el debate de las políticas públicas ${ }^{39}$. La clásica idea de representación política en los tiempos modernos se ve bastante distorsionada si se considera la natural complejidad de la sociedad y la ampliación de la base electoral, permitiendo el aumento significativo de esta complejidad y dificultando la relación representante-representado ${ }^{40}$. En este punto, se considerará que los partidos identifican las demandas de la sociedad, y que las representan ante las instituciones públicas, ya sea a través de su papel de gobierno o como oposición.

La expansión de la importancia de los partidos generó el tan connotado "Estado de partidos" 41 , en el que la voluntad de los partidos acaba por dirigir la voluntad de las instituciones representativas y estatales, y existe la posibilidad de que ellos confundan la voluntad popular con la suya ${ }^{42}$. En realidad, el papel principal de los partidos es filtrar las demandas sociales, trayéndolas a la esfera pública y reduciendo la complejidad inherente a cualquier sociedad moderna ${ }^{43}$. El monopolio actual de la representación por parte de los partidos genera, sin embargo, sentimientos antagónicos en la sociedad, como puede ser la desconfianza, por la que se pasa a dar cada vez menos crédito a dichas organizaciones en el sistema político ${ }^{44}$. Con todo, desde el momento en que se tiene la impresión de que el Estado de partidos está sobreponiéndose a la democracia de partidos, hay una distorsión no prevista, y no parece un problema menor, ya que el modelo normativo de democracia a partir de dichas organizaciones los vuelve obviamente indispensables ${ }^{45}$. La intervención por parte de los partidos en la relación Estado-sociedad y su consideración como elementos necesarios en esta dinámica les ha concedido un nivel de influencia quizá mayor de lo

pp. 19-39, trabajo en el que el autor trata del aumento del electorado, con la consecuente necesidad de aumento de la identificación de demandas sociales, ampliación del sufragio y la adopción de los partidos políticos como protagonistas en este proceso.

39 LuCAS Verdú (1984), p. 531.

40 Barbera (2008), p. 859.

41 García Pelayo (1986), p. 35.

42 Cf. De Vega Sánchez (1997), p. 311; García Giráddez (2003), p. 157.

43 Cf. SARTORI (1999), p. 274.

44 González Encinar (1990), pp. 75-79.

45 González Encinar (1992), pp. 30-32, y García (2000), pp. 55-59. 
que las actuales sociedades consideran aceptable desde el punto de vista de la legitimación democrática ${ }^{46}$.

Aunque existan sistemas en los que no se da el monopolio de los partidos en la función de formación y manifestación de la voluntad popular (en sistemas que admiten otras alternativas, como iniciativas populares de ley, candidaturas independientes y otros), no se pueda afirmar que las distorsiones que el comportamiento de los partidos y su "ubicación" en el Estado comporta no hayan alcanzado niveles muy altos ${ }^{47}$. Sin negar que los partidos sigan siendo esta pieza esencial en la relación entre sociedad y Estado, la función de representación ejercida por dichas organizaciones va perdiendo calidad "representativa" 48 , lo que genera no pocas distorsiones para una correcta comprensión democrática de la soberanía popular con un valor actual ${ }^{49}$, más allá de una democracia minimalista y "schumpeteriana", solo como procedimiento de elección entre élites capaces de gobernar ${ }^{50}$.

Por otra parte, si la representación es resultado del ejercicio del derecho de sufragio, y el responsable de instrumentalizar estos votos en escaños es el sistema electoral, es sabido que no hay sistemas electorales que no contemplen correctores con los que obtener el resultado más adecuado a la realidad del país donde se apliquen. Sin embargo, aunque justificadas, estas distorsiones pueden favorecer -como suele ocurrir- a los partidos mayoritarios. ${ }^{51}$ Así, el proceso de toma de

46 Cf. Carreras Serra (2004), pp. 113-114; Holgado González (2006), p. 2697.

47 No se trata de cuestionar teóricamente el ideal democrático, más bien es la identificación de un vacío entre la teoría y la praxis constitucional, que está llenándose por la "impostura", que hace que dicho vacío sea susceptible de convertirse en una "completa parodia de la realidad", en palabras de GArCía (2000), p. 59.

48 Aunque sea muy defensor de la democracia representativa, es cierto que incluso BobBIO (1983) reconoce sus límites, como también de los partidos como puente entre el Estado y la sociedad.

49 Aún más si se piensa que la crisis de los partidos ha hecho que la representación no sea más monopolio parlamentario, pero sí de diversos grupos de la sociedad, como los sindicatos y organizaciones de interés, entre otros. BARBERA (2008), p. 885.

50 Schumpeter afirma que la representación proporcional posibilita a todas las clases sociales tener una oportunidad en el gobierno, pero también tiene el poder de impedir que la democracia genere gobiernos eficientes, provocando tensión entre las fuerzas políticas. Así, para evitar este efecto, las atribuciones del Estado deberían ser transferidas a los individuos o equipos que dispongan de un apoyo electoral superior que los demás con que compiten. Todos serían libres de competir en un primer momento, pero esto podría ser peligroso para la eficacia del gobierno. SCHUMPETER (1984), pp. 346-348. Gomes Canotilho denomina esta teoría como la teoría elitista de la democracia, en la cual la democracia no sería el poder del pueblo, sino el poder de las élites para que el pueblo solamente elija las élites. Gomes Canotilho (1999), pp. 1317-1318.

51 Holgado GonzÁlez (2006), pp. 2692-2693. 
decisiones a partir de las instituciones legislativas también sufrirá las influencias de este déficit representativo, haciendo que existan intereses sociales que queden marginados o subrepresentados ${ }^{52}$. Los efectos de la combinación de los sistemas que componen la estructura política de un Estado dependerán en mayor medida de cómo se maneje su interdependencia, es decir, del grado de conexión que un sistema tiene con el otro. Lo que cabe afirmar es que, de todos modos, esta compleja y "multinivel" relación entre sistemas no optimiza actualmente en muchos casos el principio representativo ${ }^{53}$.

Con la evolución de la denominada "partidocracia" dentro de las instituciones del Estado, parece común constatar un cierto bloqueo de la función de formación y manifestación de la voluntad popular ${ }^{54}$, afectando la credibilidad tanto de la democracia como también de los propios partidos. Su actuación conjunta acaba por formar una mayoría indirecta, lo que refleja en la idea de una sola clase política, aunque teóricamente no sea así. Dicha situación genera desconfianza ante los partidos que, en vez de expresar el pluralismo existente, terminan por tener un protagonismo "exclusivo y excluyente" 55 en un Estado que debería ser democrático ${ }^{56}$. En definitiva, lo que tan solo se quiso subrayar aquí es la obvia existencia de una cierta crisis de representatividad generada por el modelo de Estado de partidos, lo que quizá pida una nueva interpretación de las funciones de los partidos y de su relación con el Estado, para que un frecuente comportamiento con perfil corporativo no se prolongue en el tiempo.

\section{LOS PARTIDOS POLÍTICOS COMO CANALES FUNDAMENTALES}

DE PARTICIPACIÓN POLÍTICA Y SU RELACIÓN CON EL SISTEMA ELECTORAL. ¿EXISTEN CONDICIONES PARA QUE LOS PARTIDOS CUMPLAN ESTA FUNCIÓN?

El pluralismo político tiene un canal directo con la democracia representati$\mathrm{va}^{57}$, ya que se trata de la participación política a través de representantes. Es la

52 Castillo Vera (1978), p. 153.

53 Y esto se agrava aún más con el modelo de campañas electorales existente actualmente, basado en la propaganda fuerte y en la imagen, convirtiendo todo el proceso electoral en un mero procedimiento de plebiscito, más que en elecciones representativas. Aragón ReYes (1999), p. 12.

54 Vega (1977), pp. 19 y ss.

55 Vega (1977), p. 20.

56 Herrero y Rodríguez de Miñón, Miguel (2003), pp. 201-202.

57 De Esteban y López Guerra (1977), p. 77. 
posibilidad de participación en las elecciones a través de los partidos políticos lo que los diferencia de las demás asociaciones políticas ${ }^{58}$.

Las organizaciones partidistas no son las únicas representantes del pluralismo, ya que un Estado social y democrático de Derecho también prima el protagonismo de otros entes de la sociedad. Es cierto que la participación a través de los partidos es solo una vía, ya que en las sociedades modernas también hay un "pluralismo organizacional" que no se puede ignorar ${ }^{59}$. Pero lo cierto es que en el actual modelo de Estado de partidos las decisiones jurídico-políticas pasan por ellos, a través del consenso que se forma entre sus componentes.

Esta función de expresión del pluralismo estaría imposibilitada si no se ofrecieran algunas garantías. Así, se puede decir que el derecho de sufragio universal activo (art. 14 de la Constitución Federal de 1988) permite que todo ciudadano tenga el derecho al voto, la oportunidad de expresar de manera formal su opción política, sin represión, de forma libre y secreta. Dichas condiciones son fundamentales para obtener una expresión genuina por parte de la sociedad, legitimando el resultado de las urnas y reflejando al máximo posible la voluntad del pueblo. Con todo, para que existan estas circunstancias de voto, es crucial respetar el principio de la igualdad, ya que todos los competidores deben encontrarse en niveles sustanciales de igualdad. Además, es importante resaltar, en este punto, que la igualdad debe actuar no solamente entre los aspirantes al cargo representativo, sino también respecto a los propios electores, tal y como está previsto en el artículo mencionado.

Hay también otro enfoque de esta función de los partidos políticos: representan una función activa en las decisiones políticas, por medio de la selección de representantes dentro de una democracia representativa y también a través de la formulación de alternativas de poder, sea componiendo el gobierno elegido por el electorado, sea como oposición para controlar al gobierno de turno. Esta función de ser instrumento de participación política es, pues, además de una función de los partidos, también una "descripción finalista" de los mismos, ya que dicha participación es el fin que los caracteriza (como también a las asociaciones con finalidad política), justificando el régimen jurídico diferenciado y otorgándoles beneficios públicos como son la financiación pública por medio del fondo partidario y el acceso gratuito a los medios de comunicación en el sistema brasileño ${ }^{60}$.

58 Grimm (1996), p. 409.

59 Ramírez (1980), p. 26; Soriano Díaz (1999), p. 267.

60 Bautista Plaza (2006), p. 15. 
Esta función de los partidos está relacionada con el derecho fundamental de participación política de los ciudadanos recogido en el artículo 14 de la Constitución brasileña. Este derecho tiene un significado muy importante no solo para la salud del sistema democrático, sino también como factor de armonía en las relaciones entre Estado y sociedad ${ }^{61}$. Objeto de muchas luchas, la participación política fue muchas veces suprimida como manera de bloquear cualquier demanda venida desde el pueblo que pretendiera cambiar el statu quo vigente. Así, no fue raro que el derecho de sufragio - principal manifestación de este principio- tardara en ser introducido en los países occidentales o que en muchas oportunidades fuera omitido justamente para el sostenimiento de algún régimen totalitario.

El hecho es que el constituyente dejó claro que la vía principal de participación y de hacer efectivo el principio democrático es la participación representativa, no dejando mucho espacio en concreto para las vías de participación directa. Dentro de este principio de participación representativa se incluye el derecho de sufragio universal libre, directo y secreto en los diversos niveles del gobierno, de ahí que, lógicamente, los partidos asuman el protagonismo ${ }^{62}$.

La esencia de dicho derecho es justamente la participación política stricto sensu, el derecho al voto, principal componente en el proceso electoral y portavoz de la voluntad popular. El derecho de sufragio activo se constituye como un derecho neutro, porque no se verá afectado en caso de cambios en las normas sobre el proceso electoral o el sistema electoral, entre otros, y que tiene a la vez un carácter exclusivamente político, por dedicarse solamente a formar la voluntad popular. Por no tener intermediarios, también es un derecho de ejercicio directo, periódico y, más aún porque, debido a su proyección institucional y por constituirse como un elemento importante en el proceso electoral la periodicidad necesaria en la recomposición de las instituciones representativas, pide la renovación de dicho derecho dentro de un determinado período de tiempo ${ }^{63}$. Sin embargo, también se puede afirmar que dicho derecho es una de las expresiones del pluralismo, ya que es a través del voto como el elector declarará su preferencia electoral, en el intento de elegir a sus representantes, corroborando así las funciones de los

61 En este sentido, es de resaltar que, al tratarse de un derecho fundamental, posee una naturaleza dual, es condición objetiva de la propia democracia (al asegurar la protección de las minorías y el respeto al pluralismo político), y a la vez tiene un perfil subjetivo, alcanzando directamente al sujeto tanto como elector como también como representante electo. García Roca (1999), pp. 102 y ss.

62 Carreras Serra (2001), pp. 187-188.

63 En este sentido, cf. GarCía Guerrero (2007), pp. 197-198. 
partidos $^{64}$. Por lo tanto, el art. 14 traduce la obligatoriedad de que el Estado de partidos esté abierto a la recepción de toda y cualquier expresión política venida desde la sociedad, estando prohibido su cierre efectivo, directa o indirectamente ${ }^{65}$.

Con ello, la igualdad de condiciones en la competición electoral es la pieza clave para que los partidos puedan constituirse como canales fundamentales para la participación política. En este caso, la igualdad de oportunidades bajo la perspectiva del elector y sus implicaciones en el derecho de sufragio libre es determinante.

La igualdad de oportunidades tiene una natural influencia en el voto y se refiere ante todo al sufragio activo, al derecho de los ciudadanos a declarar cuál es su opción política por medio del voto libre en elecciones periódicas, teniendo su voto un peso igual a otro emitido dentro del mismo país. Debido a ello, factores como el sistema y la barrera electoral pueden alterar directamente dichos elementos del sufragio activo, generando desigualdades y "tipos" de voto ${ }^{66}$. Si hay una discriminación injustificada de los votos y, por consiguiente, de los ciudadanos con derecho al sufragio libre, no solo se vería afectado el derecho de participación política, sino que resultaría también perjudicada la condición obligatoria de igualdad en el resultado de las urnas. Por ello la elección de un sistema electoral u otro es pieza clave en esta dinámica.

\section{El DeRECHO DE ParTiCipaCión POlítica}

\section{Y LECCIONES DE LA DEMOCRACIA PARTICIPATIVA Y DELIBERATIVA}

ANTE LAS LIMITACIONES DE LA REPRESENTACIÓN POLÍTICA

Antes de adentrar al tema específico de los sistemas electorales en un contexto de crisis de representación, es menester que se aborde el derecho de participación política por medio del enfoque de la democracia participativa y deliberativa, no con el objetivo de sustituir la democracia representativa, sino el de plantear la problemática dentro de un marco más amplio de lo que se entiende por democracia.

Las ciencias sociales se ocuparon directamente en la formulación de una tipología que pudiera clasificar las distintas formas de participación política, como persuadir a otros ciudadanos a votar; trabajar activamente para partidos

64 Cf. Presno Linera (2000), pp. 27-28.

65 En este sentido y en el contexto de los países desde donde los autores vienen, cfr. Rodríguez Días (1989), p. 234, y MORLOK (2000), p. 49.

66 Fernández Vivas (2007), pp. 57-59. 
y candidatos; participar de reuniones políticas o comicios; contribuir con recursos económicos a las organizaciones partidistas; afiliarse a una asociación; participar activamente en asociaciones o fundaciones comunitarias para la resolución de problemas, y tantos otros canales ${ }^{67}$. Este listado de actividades que se configuran en participación política permite afirmar que, en algunas de ellas, es necesario tiempo; en otras, habilidades, y, en otras, dinero ${ }^{68}$. Sin embargo, en prácticamente todas hay un alcance colectivo de sus resultados, siempre basándose en una participación activa, más allá del restricto concepto de participación política únicamente por el voto ${ }^{69}$.

Esta concepción limitativa de participación política solamente al ejercicio del voto y que se conecta mucho con la democracia representativa, puede ser fruto de la confusión que se tiene de este derecho con los efectos de la apatía por parte de los ciudadanos ante el sistema político ${ }^{70}$. Es indudable que los niveles de abstención electoral vienen aumentando, reflejo de una cierta desilusión con la política y con el aumento de formas alternativas de participación política que van más allá de su acción aislada y que realiza algo verdaderamente colectivo desde grupos sociales formales o informales ${ }^{71}$. El hecho es el que el concepto de participación política actualmente extrapola su perfil jurídico de derecho fundamental individual que se expresa por medio del voto y pasa a ser percibido en la esfera colectiva, a través de la organización de ciudadanos en grupos u organizaciones motivados por intereses en común, lo que fortalece el alcance de sus demandas y supera la debilidad de la influencia individual de cada uno de ellos, dándoles más opciones de canales de participación, más allá de los partidos políticos. Elegir la manera de cómo participar es también la concreción de este derecho que no puede ser injustificadamente limitado al actuar individual y unitario ${ }^{72}$. La noción de participación que se aboga aquí va mucho más allá de la libertad de expresión, del derecho de voto o de ser votado, sino que atiende a una lógica más amplia y que incluye también a las personas jurídicas como verdaderos actores en la esfera deliberativa pública, que sufren los mismos impactos de políticas públicas como

67 Verba y Nie (1972), p. 72.

68 Verba, Nie y Kim (1971), pp. 55 y ss.

69 Verba, Schlozman y Brady (1995), p. 48.

70 Cunha, Epple y Herath (2014), p. 986.

71 BRITO (2014).

72 Dallari (1999), pp. 85 y ss. 
todos los ciudadanos y que están democráticamente legitimados a defender sus intereses y en participar de la política por la vía que más les convenga ${ }^{73}$.

El creciente cuestionamiento de la democracia representativa como forma de ejercicio de la soberanía hizo que se urgiera la formulación de otros medios de participación política activa por parte de los ciudadanos, en el real sentido del término ciudadanía. Junto a esto, es un hecho que uno de los grandes desafíos del Estado contemporáneo es dar la debida respuesta a las demandas provenientes de la sociedad y administrar la creciente complejidad de la sociedad moderna estatal ${ }^{74}$.

El desarrollo del concepto de ciudadanía también ha contribuido para la problemática de la participación política. Marshall confrontó la idea de ciudadanía (que supone igualdad) con la idea de clase social (que refleja desigualdad), teniendo tres fases: *civil, *política, * social. El elemento civil es compuesto por los derechos necesarios a la libertad individual, como el derecho de ir y venir, la libertad de prensa, y otros. El elemento político comprende el derecho de participar en el ejercicio del poder político, como un miembro de un organismo investido de autoridad política, o como un elector de los miembros de dicho organismo. A su vez, el elemento social se refiere a todo lo que va desde el derecho a un mínimo de bienestar económico y seguridad en el derecho de participar, por completo, hasta la herencia social y a tener una vida de un ser civilizado, según los estándares que prevalecen en la sociedad. En este sentido, ciudadanía sería un status concedido a los miembros integrales de una comunidad, haciéndolos iguales en derechos y obligaciones ${ }^{75}$.

Es esta la idea de igualdad, de equilibrio entre los beneficios y los encargos que debería -en tesis- pautar un comportamiento social colectivo, marcado por la participación activa de la gente en los asuntos públicos. En esta línea, los individuos son más que meros activistas, teniendo también un fuerte espíritu público, están dispuestos a colaborar, lo que, por otro lado, fomenta el aumento del capital social ${ }^{76}$. La cooperación voluntaria es más fácil en una comunidad que tiene un stock de capital social, entendido aquí como normas de reciprocidad y redes de colaboración cívica ${ }^{77}$.

\footnotetext{
73 En este sentido, cf. Habermas (1961), pp. 47 y ss.; Keane (2001), pp. 182-184.

74 Aunque no sea parte del objeto en estudio, es aquí que el tema Gobernanza se hace importante para entender las dificultades de manejo de la relación moderna entre Estado y sociedad. Como sugerencia de lectura, cf. Cerrillo y Martínez (2005).

75 Marshall (1967), pp. 63-76.

76 Putnam (1994), pp. 87-89.

77 Putnam (1994), p. 167.
} 
Así, la sociedad civil contribuye para la efectividad y la estabilidad de la democracia gubernamental, incluso porque sus efectos internos sobre los individuos son reflejados en los efectos externos, ampliándose por todo el contexto social ${ }^{78}$. La noción de sociedad civil expuesta por Diamond es muy ilustrativa, una vez que entiende que la sociedad civil es el dominio de la vida social organizada, que es voluntaria, que surge espontáneamente en la mayoría de las veces, que se auto-sostiene, que es autónoma del Estado y sometida a un orden jurídico o un conjunto de reglas comunes. Se difiere de la "sociedad" en general en la medida que involucra a los ciudadanos, actuando colectivamente en una esfera pública para expresar sus pasiones, intereses e ideas, intercambiando informaciones para alcanzar objetivos mutuos. También hace exigencias sobre el Estado y sobre las autoridades responsables. La sociedad civil, en este contexto, es una entidad intermedia entre la esfera privada y la estatal, lo que excluye la vida individual y en familia, o cualquier actividad introspectiva en grupo, la generación de lucro o de esfuerzos políticos para asumir el poder en el Estado. Actores de la sociedad civil necesitan de la protección de un orden jurídico institucionalizado para proteger su autonomía y libertad de acción. De esta forma, la sociedad civil no solo restringe el poder del Estado, sino que lo legitima, legitimando también a la autoridad estatal cuando esta está fundamentada en el Estado de Derecho79.

Sin embargo, también se puede enfocar la ciudadanía como una idea de emancipación del individuo, de reconocimiento de la participación social como un derecho del ciudadano y una expresión de su autonomía ${ }^{80}$. Con esto, la adopción de mecanismos de democracia participativa y deliberativa complementa la democracia representativa, sin ánimo de eliminarla, ya que tienen objetivos de colaboración y no de oposición. Nadie es más capaz de saber mejor sobre las necesidades de la sociedad que los propios ciudadanos, que conocen los problemas y que tienen demandas a ser satisfechas. Si antes los ciudadanos tenían que buscar a algún parlamentario para poseer un soporte político para sus reivindicaciones, estas herramientas de democracia participativa y deliberativa disminuyen esta obligación y conceden mayores prerrogativas de decisión a los destinatarios de las políticas públicas.

Uno de estos mecanismos que vienen siendo incorporados son los consejos populares, que no son un invento moderno. Dichos consejos son históricos y

78 Putnam (1994), p. 89.

79 Diamond (1994), p. 5.

80 Cf. Santos (1991), pp. 135-191. 
muchos de ellos fueron determinantes en diversos momentos en el mundo, como la Comuna de París y los Soviets rusos. Sin embargo, sus características siguen coincidiendo en algunos casos, como el combate a los métodos tradicionales de ejercicio de poder, el rechazo de la lógica del capitalismo, la búsqueda de otras formas de poder, autonomía y descentralización ${ }^{81}$. Importantes filósofos como Hannah Arendt subrayan la esencialidad de los consejos populares, afirmando que solamente con ellos es posible un gobierno más horizontal y con oportunidades para la participación ciudadana, denominando esto democracia de consejos (council democracy) ${ }^{82}$. En este sentido, el debate sobre los consejos como un instrumento del ejercicio de la democracia es uno de los temas de la agenda propuesta para la gestión pública, tanto de sectores liberales como los de izquierda. La diferencia es que los liberales entienden que ellos son canales de colaboración, y la izquierda los tiene como vías o posibilidades de cambios sociales, para una mayor democratización de las relaciones de poder ${ }^{83}$.

Es decir, los consejos representan una forma de participación popular en la Administración Pública, no afectando en ninguno de sus aspectos la democracia representativa. Se trata de la formación de un círculo que perfecciona la democracia, que justo por fundamentarse en la soberanía popular, debe integrar a todos en la esfera de toma de decisiones. No es solo la democracia representativa que merece reparos o que debe soportar todas las críticas por sus dificultades de manejo de la alta complejidad de la sociedad moderna. Además, la representación tampoco debe ser la única vía de participación de los ciudadanos, lo que requiere la introducción de herramientas de democracia participativa y deliberativa como forma de mejora de la representatividad. Sin embargo, esto no quiere decir que la adopción de mecanismos participativos y deliberativos excluya la necesidad de arreglos en el sistema electoral, y debido a esto es que se entiende necesario abordar la representatividad desde su clásico enfoque electoral.

\section{LA REPRESENTATIVIDAD Y LA ELECCIÓN \\ DEL SISTEMA ELECTORAL. El CASO BRASILEÑo}

Es cierto que la noción de representatividad también involucra la idea de un mandato, que es designado a personas que integrarán las estructuras del poder

81 GoHN (2006), p. 6.

82 ARENDT (1973), pp. 248-269.

83 Gohn (2006), p. 6. 
público como portavoces del pueblo. Así, para que haya una real correspondencia de la voz del pueblo y las actitudes tomadas por dichos representantes, debe existir una proporcionalidad entre estos dos elementos.

Las instituciones deben reflejar la realidad social, es decir, tener representatividad que sea proporcional tanto en el número de personas a ser representadas, como en la intención del votante que ha delegado los poderes de su representación para el destinatario de su voto. Aquí reside la legitimidad democrática, una vez que el poder viene del "demos", del consenso verificado -y no presunto- de los ciudadanos ${ }^{84}$. Con ello, la democracia representativa pide una percepción de igual valor social de todos sus miembros, teniendo tres direcciones, siendo la primera la de mandato, la segunda la de representatividad, de semejanza, de similitud entre sociedad y Estado, y la tercera, la de responsabilidad ${ }^{85}$.

En el caso brasileño, se entiende que hay un problema de desproporcionalidad en la representatividad entre la población de los estados federados, considerando que, en su acepción territorial, existen diversos estados que están sobrerrepresentados, mientras existen otros que se encuentran subrepresentados. Esto, muchas veces, es atribuido a lo que la doctrina denomina de malapportionment o, en otros términos, malaporcionamiento o sobrerrepresentación distrital ${ }^{86}$.

El malapportionment se refiere a la diferencia existente entre el porcentaje de electores de un determinado distrito y la cantidad de escaños que se asignan al mismo $^{87}$. Si se toma en cuenta el caso de Brasil, de los 142.822 .046 electores en 2014 y el total de escaños en la Cámara Baja (513), habría un escaño para cada 278.405 electores $^{88}$. Existen estados en Brasil que tienen aproximadamente este número de habitantes, lo que significaría decir que deberían elegir a un solo diputado. Sin embargo, el criterio de Dahl referente a la igualdad de voto no es posible de aplicarse ipsis literis en la práctica, terminando por construirse un sistema de premios y castigos. Todos los sistemas electorales producen algún tipo de distorsión, que en alguna medida resultan en una sobrerrepresentación distrital,

\footnotetext{
84 SARTORI (2005), p. 30.

85 Vallés y Bosch (1997), p. 18; Sartori (2005), p. 264.

86 Reynoso atribuye al término la traducción de "sobrerrepresentación distrital", una vez que el neologismo no ayuda a entender la verdadera noción de la palabra. Con todo, el "malaporcionamiento" también se ha vuelto común en los trabajos sobre el tema. Cf. ReYnoso (2002), p. 55.

87 Reynoso (2001), p. 167.

88 Datos colectados en el sitio web del Tribunal Superior Electoral (http://www.tse.jus.br/eleicoes/estatisticas/ estatisticas-eleitorais-2014-eleitorado). Acceso en 27.10.2014.
} 
con excepción de los distritos únicos. Aunque una representación estrictamente proporcional basada en términos poblacionales y de escaños podría ser o criterio más democrático, no es menos verdad que es una tarea un tanto imposible, considerando el tamaño de Brasil y su electorado disperso, como también la necesaria prevención de favorecimiento de intereses regionales que marcan a prácticamente toda la historia política brasileña ${ }^{89}$.

Existen estudios sobre dicha desproporcionalidad en la representación política brasileña que atribuyen al malapportionment las consecuencias negativas sobre la gobernabilidad y las distorsiones entre los representantes y los representados ${ }^{90}$. En este sentido, el malapportionment generalmente es visto como una patología más que una solución para eventuales desigualdades sociales y económicas en países con la magnitud de Brasil ${ }^{11}$. Los estudios que se ocuparon de analizar el tema describen que dichos desequilibrios en la representación brasileña son históricos, viniendo desde la época del Imperio, siguiendo en las Constituciones de 1934, 1946, 1969 y 1988, siendo esta última frecuentemente señalada como la que perpetúa tajantemente dicha desproporcionalidad, al mantener en el ordenamiento un número mínimo y máximo de diputados en cada estado de la federación ${ }^{92}$.

Así, no es difícil entender la razón por la cual Samuels y Snyder afirmaron que Brasil es uno de los países con el mayor nivel de desproporcionalidad de América Latina ${ }^{93}$.

Brasil ha adoptado el sistema mayoritario con doble vuelta para las elecciones de presidente de la República, vicepresidente; gobernador de Estado (en este caso, estado miembro) y su vice; alcaldes (en los municipios) y su vice. Además, para el cargo de senador de la República se aplica el sistema mayoritario con mayoría simple ${ }^{94}$. Por otro lado, el sistema proporcional fue instituido para las elecciones

\footnotetext{
89 Reynoso (2001), p. 56; Nohlen (2011), pp. 168-169.

90 Cavalcante y Turgeon (2012), pp. 2-3.

91 Reynoso (2002), p. 56.

92 Tavares (1995), p. 196; Bohn (2006), pp. 194-196.

93 SAmuels y SNyder (2001), pp. 652-653. Aquí cabe una observación: aunque los autores hayan llegado a conclusiones muy claras, en la perspectiva comparada que ellos proponen en su trabajo, al menos para el caso brasileño, existen algunos factores que no fueron tenidos en cuenta para la conclusión sobre su desproporcionalidad. Aun así, sus resultados se aproximan mucho a la realidad.

94 En la redemocratización de Brasil se nota que se adoptó la lección de Duverger, que aduce que "el primer efecto de la representación proporcional es, pues, impedir cualquier evolución hacia el bipartidismo: se puede considerarla, a ese respecto, un freno poderoso". Duverger (1967), p. 283. Para el autor, "los diputados
} 
de diputados estatales (miembros de las asambleas legislativas de los estados miembros) y de la Cámara de Diputados Federales o Cámara Baja, y de concejales (en portugués "vereadores") en los municipios. Ante esto, el análisis de una eventual crisis de representatividad solo no se ve perjudicado si se compara con el sistema proporcional empleado para la designación de estas cámaras parlamentarias, justificando aquí un recorte en el objeto de este trabajo.

El sistema proporcional brasileño sigue muchos otros modelos utilizados por otros países, como Noruega, Austria y Argentina. Existe la utilización de un cociente electoral como un umbral que determina cuáles son los partidos que acceden al reparto de los escaños (también conocido como la cuota Hare), para luego calcularse el cociente partidario, responsable de determinar la cantidad de escaños que serán destinados para cada partido, de acuerdo con el número de votos obtenidos por ellos.

El primer paso para la aplicación de las reglas de las elecciones proporcionales es definir cuáles son los votos que basarán el cálculo del cociente electoral, restando los votos blancos y nulos del total habido en las urnas. El número de votos válidos (resultado de dicha sustracción) es dividido por el número de escaños que se disputan, siendo el resultado de esta operación el cociente electoral, según el art. 106 del Código Electoral ${ }^{95}$.

En seguida, los votos de cada partido son divididos por el cociente electoral, formando el cociente partidario y determinando la cantidad de escaños destinados a cada uno de ellos. Se desprecia las fracciones de números obtenidos en un primer momento, siendo reconsiderados en el cálculo de las "sobras" de los escaños. Así, los escaños destinados para cada partido serán ocupados por los candidatos más votados por la organización, según el art. 107 del Código Electoral de Brasil.

Dicha proporcionalidad es combinada con un sistema de lista abierta, que es definida solamente después de las elecciones. En el sistema cerrado, más común, el elector vota en una lista preordenada por el partido o coalición, y los candidatos mejor ubicados en esta lista son los que restan electos, de acuerdo con la proporción de votos obtenidos. En la lista abierta es al revés, ya que el elector vota en el candidato y no en el partido. El número de escaños ocupados por un partido o coalición es proporcional al número de votos que sus candidatos han logrado en conjunto, lo que significa decir que, si un candidato popular es capaz de traer votos, él garantiza a

representan sus electores no como un mandatario que representa un mandato, pero como una fotografía representa un paisaje, un retrato, un modelo". DUVERger (1967), pp. 387-408, o al menos así debería ser.

95 Nicolau (1997); Saisi (2007). 
su partido diversos escaños, aunque la organización sola haya obtenido pocos votos. Dicho sistema vuelve al partido un "rehén" del candidato más popular, que aunque no tenga una identidad con el programa partidista, es electo y termina debilitando la organización. Esta es una de las razones por las que existe una proliferación de candidaturas de personas como cantantes "pop", deportistas, actores y actrices de la televisión, etc. Es lo que se conoce por efecto "arrastre" 96.

Cabe resaltar que las sobras de escaños son distribuidas por medio de la fórmula D'Hondt. El total de votos de cada partido o coalición es dividido por el número de escaños que dicho partido ya haya obtenido, más uno. Dicha fórmula innegablemente favorece a los partidos que obtuvieron más votos, ya que las organizaciones con las mayores medias de votación reciben más escaños, justamente aquellos que no fueron distribuidos en la primera etapa ${ }^{97}$.

La cuestión es verificar el grado de exactitud entre la voluntad de la nación y la voluntad del parlamentario, considerando que existen dos deformaciones de opinión, una en el porcentual del sufragio comparado al porcentual de escaños en el Parlamento; y otra, que es más grave, referente a la variación entre la distribución de los sufragios y la verdadera naturaleza de opinión, ya que el sufragio no refleja una opinión pública propiamente dicha, sino el medio de expresar dicha opinión, que acaba deformándola ${ }^{98}$.

Como es sabido, el sistema proporcional tiene como ventaja la garantía que se ofrece a las minorías contra los abusos de las mayorías. Sin embargo, puede generar inestabilidad del gobierno, gobiernos de coalición con poca fidelidad en los acuerdos políticos, principalmente en lo que se refiere a la estabilidad gubernamental, o aun la disolución de la responsabilidad de los parlamentarios ante el electorado 99 .

\section{Distorsiones PRODUCIDAS POR EL SISTEMA PROPORCIONAL BRASILEÑO}

La aplicación de cocientes electorales y partidarios para la distribución de los escaños por sí sola genera distorsiones. Sin embargo, no es la única razón para los problemas de desproporcionalidad en el sistema brasileño. Una de las principales causas señaladas por la literatura es la que se refiere a la regla constante en la Constitución Federal de 1988, que establece un número mínimo y máximo de

\footnotetext{
96 WefFort (2009).

97 SoARes y LORENÇO (2004).

98 Duverger (1967), p. 407.

99 Воввіо (1992), р. 1176.
} 
representantes por cada estado de la federación (art. 45, Constitución Federal) ${ }^{100}$, conjuntamente con la no revisión periódica del número de representantes de cada circunscripción electoral en la Cámara Baja. Dichos elementos conjugados provocan una fuerte desproporcionalidad en la representación territorial.

La evolución histórico-jurídica de la regla del "mínimo-máximo" se inició en 1977, bajo el gobierno autoritario-militar de 1964. La enmienda constitucional No 8 había establecido un número mínimo de seis y el máximo de cincuenta y cinco diputados federales por estado. Dicha enmienda garantizó aun que cada territorio en Brasil, que correspondía a espacios federales que no formaba, jurídicamente, un estado miembro, tuviera dos diputados en la Cámara Baja. A su vez, la enmienda No 22 de 1982 ha cambiado dichos límites, aumentándolos de seis para ocho el mínimo, y de cincuenta y cinco para sesenta el máximo de diputados por estado miembro. Dicha alteración también alcanzó a los territorios mencionados que, de los dos diputados de antes, pasaron a tener cuatro. La regla actual fue establecida por la Constitución de 1988, que ha aumentado el máximo de diputados por estado a setenta, manteniendo el número mínimo. Estableció, asimismo que cada territorio será representado por 4 diputados federales, aunque en este momento no haya ningún territorio federal en Brasil, ya que aquellos antes existentes fueron transformados en Estados en $1988^{101}$.

Además, no se produjo directamente una separación y delimitación de distritos electorales, una vez que ya existían los estados federados ${ }^{102}$ ya separados desde la época del Brasil Colonia, con las capitanías hereditarias y el posterior proceso de creación de dichos espacios territoriales ${ }^{103}$.

Siendo una federación, Brasil se encuentra dentro de una problemática muy seria en lo que se refiere a la representación política. El sistema federal enfatiza la representación territorial al garantizar una cierta autonomía política a las subunidades nacionales y al incorporar la representación de dichas subunidades en el poder central. Con ello, hay una dualidad en la representación política de las federaciones y un dilema: volver a las regiones políticamente más iguales o volver a todos los ciudadanos más iguales ${ }^{104}$. Dicho dilema debería ser resuelto con la

\footnotetext{
100 TAVAREs (1995), p. 194.

101 SoARES y LOURENÇO (2004).

102 La división de las circunscripciones electorales coinciden con los estados miembros debido al art. 86 del Código Electoral Brasileño (ley No 4.737/65).

103 VAllés y Bosch (1997), p. 122.

104 SoARES y LOURENÇO (2004).
} 
estructura bicameral en la que el Senado asegura la representación igualitaria a los Estados miembros, y la Cámara de representación proporcional, que considera mayoritariamente el criterio demográfico. Sin embargo, esto no ocurre porque tanto el Senado como la Cámara terminan por poseer potestades muy similares, dificultando el equilibrio federativo que el bicameralismo, en tesis, proporcionaría. Ante esto, claro está que, si el federalismo es algo relevante y que debe ser priorizado en la estructura del Estado brasileño, siendo los estados unidades territoriales, no se permite que exista una representación estrictamente proporcional basada en el criterio demográfico. El federalismo ${ }^{105}$, en este caso, sería un freno al poder de la mayoría, en una expresión del principio consensualista ${ }^{106}$.

Entre el dilema de tener que elegir entre la proporcionalidad demográfica y la territorial, es justamente aquí que la desproporcionalidad del sistema brasileño se hace notar, ya que solo entran en la distribución de escaños los partidos o coaliciones que alcancen el cociente partidario igual o mayor que uno. Caso contrario, aunque dicho partido tenga un candidato con una expresiva votación individual, él no va a elegir ningún parlamentario ${ }^{107}$. Ante eso se hace evidente que tanto el cociente electoral como el partidario cambian de estado a estado. No hay un criterio -o un umbral- uniforme para todo el territorio brasileño ${ }^{108}$.

105 Es sabido que el federalismo brasileño es peculiar si comparamos a otros países, como Estados Unidos. En Estados Unidos la Federación se formó a partir de la unión de sus antiguas colonias que, independientes, formaron los Estados Unidos de América, con la constitución de un gobierno central representado por la Unión. Y es lo que se considera una federación por agregación o federación centrípeta. En Brasil ocurrió al revés: la federación fue una concesión del Estado Unitario, típico del Brasil Imperio, a la recién República, proclamada en 1889, dando origen a la federación por segregación o, en su origen, una federación centrípeta. Sin embargo, su funcionamiento está lejos de ser como determinaba el pacto federativo. Con la promulgación de sucesivas constituciones, poco a poco se fueron quitando potestades de los estados miembros y centrándolas en el gobierno federal. La Constitución de 1988 -actualmente vigente- deja poco margen de autogobierno y regulación para los estados miembros, aunque todavía detentan algo de competencias. Lo que sí es cierto es que los estados miembros son muy dependientes del gobierno central. La fuerte dependencia fiscal que los estados tienen de los recursos económicos venidos desde el pago de impuestos al gobierno central hace que ellos estén considerablemente sumisos a las políticas venidas desde esta gigante máquina, lo que impide significativamente el desarrollo de dichos entes de la federación. Es importante destacar que la Constitución de 1988 confiere a los Estados miembros autonomía, y no soberanía, conforme el art. 18. Cf. MoraEs (2006).

106 LIJPHART (1999), p. 20. La palabra original encontrada es "consociativa", pero no fue posible encontrar una traducción directa para dicho término, obligando a una aproximación con el sentido de consenso.

107 SAISI (2007).

108 Considerando la multiplicidad de cocientes electorales, termina por surgir lo que se llama de valor absoluto, o el coste absoluto, en votos de cada candidato a diputado federal, que disminuye más de lo proporcional a la disminución del número de votos válidos, incluidos los votos en blanco, en el estado. Dicha evidencia explica por qué hay empresarios de São Paulo, por ejemplo, que prefieren apoyar económicamente 
El establecimiento de un número mínimo y máximo de representantes por la Constitución es tenido como la mayor responsable de los efectos dañinos del sistema proporcional, una vez que, al contrario de compensar el alejamiento entre niveles económicos y sociales de las regiones de Brasil, acaba por provocar una importante distorsión entre ellas, generando a la postre diferentes pesos entre los votos, lo que viola el principio de "one man, one vote"109, y manteniendo dichas diferencias de desarrollo entre las partes afectadas del país ${ }^{110}$.

En lo que se refiere a la ausencia de revisión periódica del número de representantes de cada estado con relación a su población actual, el último censo realizado fue en 1993, aunque el Tribunal Superior Electoral ${ }^{111}$ ya haya intentado actualizar los datos en otras oportunidades, como ocurrió en 2012 y en 2014 pero que, debido a fuertes presiones de los estados que perderían diputados, no se llevó a cabo al final. De esa manera, el Tribunal Superior Electoral nada más hace que aprobar resoluciones que terminan siendo declaradas inconstitucionales o siendo rechazadas en las casas legislativas, sin que exista una alteración formal en el número de diputados, algo que, para parte de la doctrina, es positivo, ya que se entiende que esta tarea debería permanecer con el Parlamento y no en un órgano del Poder Judicial ${ }^{112}$.

Otro punto de extremada relevancia en el análisis es que, antes de la redemocratización, en Brasil había muchos territorios que no eran jurídicamente estados federados. Empero, a partir de los 80, se produjo la transformación de estos territorios en estados miembros, ya con el reconocimiento constitucional correspondiente. En 1962 el estado de Acre (extremo norte del país) ha dejado

a los candidatos en las elecciones de los estados menos poblados, una vez que su apoyo les costará menos en comparación con los candidatos de su propio estado. Nicolau (1996), pp. 197-213. Existen diversos estudios sobre lo que se llama de sesgo partidario, que es el desequilibrio entre el "coste" de votos en estados federados distintos para que un mismo partido logre escaños. En este sentido, cf. TAVARES (1995); ReYNoso (2002); Cavalcante y Turgeon (2012).

109 Nicolau (1997).

110 ReYNOSO (2001), p. 169.

111 El TSE, o Tribunal Superior Electoral, es el órgano máximo de la justicia administrativa electoral de Brasil. Es responsable de organizar las elecciones, coordinarlas y aplicar la legislación electoral. También tiene potestades jurisdiccionales, siendo una justicia especializada y aparte de la común.

112 Teixeira da Mata (2001), p. 5. Dicha ausencia de revisión poblacional y la proporción de escaños es señalada como la responsable de producir distorsiones que carecen de una explicación lógica, como el hecho de que el Estado de Pará, que tiene una población mayor que la población de Maranhão, tenga un diputado a menos, y el Estado de Santa Catarina, con una población superior a la del Estado de Goiás, también tenga un diputado a menos en la Cámara Baja. RABAT y CASSIANO (1997). 
su condición de territorio para volverse un estado federado; en 1979 fue creado el estado de Mato Grosso do Sul, a partir del desmembramiento del estado de Mato Grosso, en el centro. En los ochenta, fueron integrados otros cuatro nuevos estados: el territorio de Rondônia (también extremo norte) se ha vuelto estado en 1981; por cuenta de la Constitución de 1988, Roraima y Amapá (junto con Rondônia en el extremo norte), también fueron transformados en estados, como también el estado de Tocantins, con la división del estado de Goiás (centro del país) ${ }^{113}$.

La creación de nuevos estados frecuentemente es motivada por ventajas políticas y económicas que son concedidas a las localidades que se vuelven estados, sobre todo en regiones menos pobladas y más pobres. Fuera las ventajas fiscales de institución de impuestos propios de los estados, la estructura completa de la administración pública que debe haber representa una importante cantidad de recursos económicos. Además de sus representantes a nivel estatal y local, son más de ocho diputados federales mínimo y 3 senadores, que se traducen en la práctica como un equipo para lograr más subvenciones del gobierno federal dentro de las instituciones ${ }^{114}$. La lógica se vuelve aún más nefasta si se piensa que, cuanto más pobre es la región, mayores son los incentivos en volverse un estado una vez que hay pocos obstáculos para ello. Cabe resaltar que la Constitución de 1988 condiciona la creación de nuevos estados únicamente a elementos políticos, no habiendo ningún criterio demográfico o económico ${ }^{115}$.

Dicho escenario, considerado junto con el límite constitucional de representantes por estado fijado por la Magna Carta, hace que cinco de estos seis estados estén sobrerrepresentados en la Cámara Baja, mientras que los estados más populosos se encuentren subrepresentados, con una cantidad de diputados muy inferior al tenido como necesario para representarlo proporcionalmente.

Traduciendo en números dicha desproporcionalidad, se tiene que en estados con poca población, como es el caso de Amazonas y Acre, eligen a ocho diputados federales como mínimo, mientras que São Paulo, el estado con la mayor población

\footnotetext{
113 SoARES y LOURENÇO (2004).

114 TAVARES (1995), p. 205.

115 El último intento de crear estados en Brasil ocurrió en 2011, por medio de un plebiscito que objetivaba dividir al estado de Pará (norte de Brasil) en tres estados: Pará, Carajás y Tapajós. Más del 66\% del electorado ha votado en contra de dicha separación, muy probablemente influida por la fuerte campaña realizada principalmente en los medios y en las redes sociales del alto coste de eso, sin un fin necesario que pudiera justificarlo. Nuevamente, cabe destacar que el norte de Brasil es una de las regiones que más sufre con las desigualdades económicas y sociales.
} 
de Brasil, tiene solamente setenta representantes, quedándose subrepresentado en la Cámara Baja ${ }^{116}$. Dicha desproporción en la representación política de los ciudadanos produce efectos poco adecuados para una democracia tan joven como es la brasileña. El peso de los votos de los ciudadanos que viven en los estados menos poblados es mayor que el peso de los votos de los ciudadanos que viven en estados con más habitantes. En términos porcentuales, São Paulo, con $22 \%$ de la población total de Brasil, necesitaría tener 22\% del total de los 513 escaños de la Cámara de Diputados, que son, o sea, necesitaría de 113 diputados en el lugar de los 70 que tiene actualmente. Por otro lado, el estado de Roraima, que tiene 0,16\% del total de la población de Brasil, elegiría únicamente a un diputado, y no a los ocho actuales, conforme determinación constitucional. Transfiriendo esto para los datos referentes a las elecciones de 2010, el estado de São Paulo necesitaría alrededor de 280.000 votos para elegir un diputado, mientras que en el estado de Roraima serían necesarios únicamente 21.000 o menos votos para elegir un diputado en la Cámara Baja ${ }^{117}$. Se podría mencionar el caso de los votos válidos en el estado de Amapá, con un electorado total de 213.000 votantes, serían insuficientes para elegir un único diputado en los estados de Minas Gerais, Rio de Janeiro, Rio Grande do Sul, Paraná y São Paulo. Otra vez más cabe subrayar que el estado de Amapá elige actualmente a ocho diputados en la Cámara de Diputados.

Además, es oportuno señalar que la ausencia de una revisión periódica del número de representantes de cada circunscripción electoral en la Cámara Baja también colabora sobremanera a este resultado distorsionado, ya que comúnmente existen alteraciones debido al desplazamiento interno de la población en el país o derivadas de diferentes patrones regionales de crecimiento poblacional. Esto hace que algunas partes del país sigan estando sobrerepresentadas y otras subrepresentadas, agudizando la condición anteriormente mencionada ${ }^{118}$.

El aumento artificial de la representación política de algunas regiones de Brasil se refleja en otros aspectos, como puede ser una de las causas de la no realización de las reformas sociales necesarias en el país. Es un hecho que existen regiones en Brasil donde predomina una cultura política antigua, tradicional, que puede ser identificada por los grandes latifundistas, coroneles y otros estándares clientelistas poco republicanos. Sin embargo, el sistema electoral aplicado tampoco colabora para mejorar dicho panorama. Al aumentar el poder político de esta élite dirigente

\footnotetext{
116 Nicolau (1997).

117 Soares y Lourenço (2004); Cavalcante y Turgeon (2012), p. 5.

118 Nicolau (1997).
} 
y que coordina dicha cultura política regional por medio de su sobrerrepresentación en la Cámara Baja, la propia actividad legislativa se ve afectada, impidiendo que medidas normativas sean concretadas a favor de un equilibrio de la federación ${ }^{119}$.

En este sentido, existe la hipótesis de, al representar sobradamente a las élites de las regiones más desfavorecidas social y económicamente de Brasil, la Constitución no lo hace para mejorar o mitigar dichas desigualdades. El efecto mediato de ello es la sumisión creciente de los ciudadanos de estas áreas a estas élites, que no desean nada más que perpetuarse en el poder sin que ello conlleve a un desarrollo en la realidad de aquella parte del país. Como ya se ha dicho, muchas reformas de carácter social fueron directamente bloqueadas por el veto de dichas élites en el Congreso Nacional, manteniendo a estos ciudadanos en la misma situación de antes de la redemocratización. Dicha hipótesis es sostenida por Giusti Tavares desde los 90, pero todavía sigue muy aplicable al día de hoy, una vez que, pasados más de 15 años, la situación de pobreza de dichas regiones permanece o igual o peor que antes ${ }^{120}$.

Ahora bien, existe otro punto de vista más positivo sobre la existencia de esta desproporcionalidad en la representación política en Brasil. La subrepresentación de los estados más poblados y la consecuente sobrerrepresentación de los estados tenidos como menores no solo no violan los principios de la representación política, sino también compensa a los estados en "desventaja" por el alto coste para la obtención de escaños en dichas circunscripciones. Sería como un combate a la tiranía de la mayoría sin utilizarse de un veto de la minoría. En este sentido, la diferencia de desarrollo social y económico entre los territorios de Brasil justifica dicha desproporcionalidad en la representación. Se entiende que el propio pacto federativo impone la colaboración entre los estados por medio de un acuerdo de las entidades federativas más pobladas y más desarrolladas en conceder parte de su representación a favor de las menos pobladas y que necesitan de más influencia en el gobierno central, como una forma de equiparación ${ }^{121}$.

Por otro lado, existen autores que entienden que no hay comprobación de la relación directa entre subrepresentación y desarrollo socioeconómico, sobre todo

\footnotetext{
119 Nicolau (1997).

120 TAVAREs (1995) p. 203. Aquí no se considera el pequeño desarrollo económico que las regiones más pobres han tenido en los últimos años debido a políticas públicas adoptadas por el Poder Ejecutivo y no el Legislativo. Además, en estas áreas las prácticas electorales poco o nada han cambiado, prevaleciendo el tradicional caudillismo sobre las clases menos favorecidas.

121 Nicolau (1997).
} 
porque la desproporcionalidad se puede encontrar en todas las regiones de Brasil, en estados de diversos niveles de desarrollo ${ }^{122}$.

Asimismo, es perceptible que dicha condición de desproporcionalidad fue tenida en cuenta en el momento de la elaboración del sistema electoral a ser aplicado, y por esto se optó por técnicas como el malapportionment ${ }^{123}$. En casos de países federados como Brasil, el bicameralismo tiende a disminuir dicha desproporción en la representación, lo que no ocurre en Brasil, ya que cada estado brasileño elige a tres senadores. El efecto directo de esto es que se termina por agravar aún más la desproporción, una vez que en las regiones norte y noreste existen más estados que en la región sur y sureste, generando, quizá, una "tiranía" de lo que se entiende por "minoría".

\section{AJUSTES EN LOS PARTIDOS Y EN EL SISTEMA ELECTORAL A FAVOR DEL DESARROLLO DE LA DEMOCRACIA EN BRASIL}

El régimen democrático debe mucho a los partidos, de la misma manera que los partidos deben mucho a la democracia. No se trata de ideas antagónicas, como a veces se puede pensar, sino son ideas complementarias, iguales como debe ser considerada la relación de los partidos con la sociedad civil, que tampoco debe ser excluyente. La democracia moderna no es compuesta solamente por la representación, por los partidos o por los procedimientos que legitiman los detentores del poder. La competencia de las organizaciones partidistas con otros actores que también actúan en la arena política de ahora los hace tener que enfrentar una nueva manera de portarse ante los ciudadanos, agregando fuerzas, intereses y opiniones de forma más inclusiva, más allá del soporte electoral. Deben esforzarse para cumplir mejor esta tarea de representación, que paulatinamente fue marginada por ellos mismos ${ }^{124}$. Es indudable que cabe un cambio de actitud ante una democracia que cada vez más aporta complejidad social y desafíos de gobernabilidad $^{125}$. Uniendo factores para mejorar la sistemática política, como también revisando y actualizando la realización de sus funciones en la democracia moderna, es posible volcar este escenario y sepultar de una vez la expresión "crisis de los partidos".

\footnotetext{
122 Cavalcante y Turgeon (2012), p. 10.

123 Vallés y Bosch (1997), pp. 16 y 122-124.

124 PASQUino (1985), pp. 140 y ss.

125 Nogueira (1994), pp. 8-11.
} 
Por otro lado, es un hecho que en una democracia que todavía está consolidándose, es natural que exista un cierto recelo de la dominación de una mayoría concentrada en algunas regiones de Brasil, aunque sea una mayoría mucho más ficticia que fáctica. No se demuestra empíricamente la posibilidad de la existencia de una "tiranía de la mayoría", una vez que los mayores electorados de Brasil se encuentran en la región sureste, y aunque se produzca una fiel alianza de dichos estados (São Paulo, Rio de Janeiro, Espírito Santo y Minas Gerais), no se alcanza una mayoría que tendría poder como para comportarse así. Tampoco es factible la unión de regiones en perjuicio de otras, considerando que Brasil tiene un tamaño continental y que sus diferencias internas todavía tienen un fuerte peso en este sentido ${ }^{126}$.

Lo que sí es cierto es que ha llegado el momento de alterar las reglas vigentes de reparto de escaños entre los estados brasileños, como, por ejemplo, eliminándose el mínimo constitucional de diputados por estado, aunque se sabe que esto difícilmente va a ocurrir, ya que afecta a asuntos de renombrada importancia económica, como cuestiones fiscales resultado de la composición actual de la Cámara Baja. Otra providencia -aunque muy polémica en términos de respeto a la diversidad social de Brasil- sería adoptar el sistema distrital de votos, que de hecho es uno de los puntos incluidos en la pauta de la eterna reforma política brasileña. Muchos abogan que una nueva división de las circunscripciones electorales podría disminuir dichas distorsiones causadas por el sistema proporcional. No obstante, hay un temor de que, con dicho sistema, se institucionalice la dominación regional de partes del país, realidad esta que ya hace parte del cotidiano de algunos estados. La división en distritos menores podría favorecer aún más a la proliferación del caudillismo, algo que en definitiva no es democrático. Sin embargo, debido al recorte realizado en el objeto de este trabajo, se mantendrá aquí solamente la primera sugerencia de la eliminación del mínimo de diputados federales por estado.

Por lo tanto, una de las únicas soluciones que se podría señalar es una reforma constitucional en el número máximo y mínimo de diputados federales. Se adhiere a la idea de que, eliminando el número mínimo, se podría alcanzar algún resultado que favoreciera a la proporcionalidad, disminuyendo la sobrerrepresentación de los estados miembros que actualmente son muy poco poblados, aunque el efecto de dicha medida no sería del todo suficiente como para sanar el problema.

126 TaVARes (1995), p. 211. 
Sin embargo, el tema cobra mucha seriedad, principalmente si se tiene en cuenta que ya se verifican algunos puntos de conflicto entre regiones del país, que por no saber técnicamente la razón de las distorsiones en su representación, terminan fundamentándose en temas poco igualitarios, generando desprecio hacia los ciudadanos del noreste o rechazo de los ciudadanos del sureste. Un claro ejemplo de discriminación interna entre brasileños que no es para nada aconsejable en un contexto de Estado social.

Y no menos importante, problemas como la pobreza, la desigualdad social y otros que son profundizados siempre que existen problemas de representatividad política en las instituciones públicas merecen especial atención. Aunque no haya comprobación directa sobre el impacto de la desproporcionalidad sobre la realidad socioeconómica de determinadas regiones, es un hecho que culturas (y por qué no decir familias) poco democráticas permanecen en el poder ayudadas también por las reglas que generan efectos desproporcionales. Empero, como dichos problemas son enfocados de manera distinta, aparentando que están separados de los problemas de coyuntura política, poco o nada se hace en contra de los verdaderos desafíos sociales de Brasil desde la esfera del sistema político.

\section{BiBLIOGRAFÍA CITADA}

Álvarez Conde, E. (1991): “Los principios del Derecho Electoral”, en Revista del Centro de Estudios Constitucionales (No 9, may./ago.), pp. 9-37.

Aragón ReYes, M. (1999): "Democracia y representación: dimensiones subjetiva y objetiva del derecho de sufragio", en Orozco Henríquez, J.J. (coord.), Memoria del III Congreso Internacional de Derecho Electoral (vol. 1, [s.l.]), pp. 3-24.

Arendt, H. (1973): On revolution (UK, Pelican Books).

Barbera, A. (2008): "La rappresentanza politica: un mito in declinio?", en Quaderni Costituzionali (Anno XXVIII. No 4, diciembre), pp. 853-886.

Bastida Freijedo, F.J. (1987): "Derecho de participación a través de representantes y función constitucional de los partidos políticos", en Revista Española de Derecho Constitucional (año 7, No 21, sep./dic.), pp. 199-228.

Bautista Plaza, D. (2006): La función constitucional de los partidos políticos (Granada, Comares).

Bobbio, N. (1983): Qual socialismo? (Rio de Janeiro, Paz e Terra).

Bobbio, N. (1986): O futuro da democracia. Uma defesa das regras do jogo (Rio de Janeiro, Paz e Terra). 
BRITO, W. (2014): “Superação da apatia política pela valorização de novas práticas de participação cidadã” [fecha de consulta: 6 de julio de 2015]. Disponible en: http://www.pucgoias.edu.br/ucg/ser/ArquivosUpload/1/file/Artigos/pdf/ superacao_apatia.pdf.

Carreras Serra, F. (2001): "Derecho de participación política”, en Aragón ReYES, M. (coord.). Temas Básicos de Derecho Constitucional. Tomo II. Tribunal Constitucional y Derechos Fundamentales (Madrid, Civitas). pp. 91-126.

Carreras Serra, F. (2004): "Los partidos en nuestra democracia de partidos", en Revista Española de Derecho Constitucional (año 24, No 70, ene./abr.), pp. 91-126.

Castillo, P. (1978): "La campaña del referéndum constitucional", en Revista de Estudios Políticos (No 6, Centro de Estudios Constitucionales), pp. 153-174.

Cavalcante, P.; Turgeon, M. (2012): "Desproporcionalidade da representação legislativa: análise dos efeitos sobre o sistema partidário no Brasil”, [fecha de consulta: 12 de septiembre de 2014]. Disponible en: http:// www.anpocs.org/portal/index.php?option=com_docman\&task=doc_ view\&gid $=8129 \&$ Itemid $=76$.

Cerrillo y MarTínez, A. (2005): La gobernanza hoy: introducción. La gobernanza hoy: 10 textos de referencia (Madrid, Instituto Nacional de Administración Pública), pp. 11-31.

Colomer, J.M. (2001): Instituciones politicas (Barcelona, Ariel).

Cunha, C.S.; Epple, C.; Herath, M. (2014): "O direito fundamental de participação social no estado democrático de direito" [fecha de consulta: 6 de julio de 2015]. Disponible en: http://www.conpedi.org.br/manaus/arquivos/ anais/brasilia/04_365.pdf.

DAHL, R. (2002): La poliarquia-participación y oposición (Madrid, Tecnos).

Dallari, D.A. (1999): O que é participação Política? (São Paulo, Brasiliense).

Dalton, R.J.; McAllister, I. (2007): "Political Parties and political development: a new perspective”, en Party Politics (vol. 13, No 2), pp. 139-140.

De Esteban, J.; López Guerra, L. (1983): El régimen constitucional español 1 (Barcelona, Labor).

DiAmond, L. (1994): "Rethinking civil society: toward democratic consolidation" en Journal of Democracy (v. 5, No 3, july), pp. 4-17.

Duverger, M. (1970): Instituciones politicas y Derecho Constitucional (5a ed., Barcelona, Ariel).

Dworkin, R. (1996): Freedom's Law: The moral reading of the American Constitution (Cambridge, Harvard University Press). 
Esparza Oroz, M. (2004): La ilegalización de Batasuna: El nuevo régimen jurídico de los partidos politicos (Cuadernos Aranzadi del Tribunal Constitucional, Navarra, Thomson/Aranzadi).

Fenichel Pitkin, H. (1985): El concepto de representación (Madrid, CEPC).

FERNÁNDEZ VIVAS, Y. (2007): Igualdad y partidos políticos: análisis constitucional y comparado de la igualdad de oportunidades de los partidos políticos (Madrid, Congreso de los Diputados).

Fernández-Miranda Campoamor, C.; Fernández-Miranda Campoamor, A. F. (2003): Sistema electoral, partidos politicos y parlamento (Madrid, Colex).

García Giráldez, T. (2003): "Los partidos políticos y el Derecho", en VV.AA. Curso de Partidos Políticos (Madrid: Akal), pp. 141-170.

Garcia Guerrero, J.L. (1990): "Algunas cuestiones sobre la constitucionalización de los partidos políticos", en Revista de Estudios Políticos (nueva época) (№ 70, oct./dic.), pp. 143-183.

García Guerrero, J.L. (2007): Escritos sobre Partidos Políticos (cómo mejorar la democracia). (Valencia, Tirant lo Blanch).

García Roca, J. (1999): Cargos públicos representativos - Un estudio del artículo 23.2 de la Constitución (Pamplona, Aranzadi).

García, E. (2000): El estado constitucional ante su 'momento maquiavélico' (Madrid, Civitas).

García-Pelayo, M. (1986): El estado de partidos. Madrid: Alianza.

Gohn, M.G. (2006): "Conselhos gestores e gestão pública", en Ciências Sociais Unisinos (v. 42, No 1, jan./abr.), pp. 5-11.

Gomes Canotilho, J.J. (1999): Direito Constitucional e Teoria da Constituição (3 $3^{\text {a }}$ d. reimp., Coimbra, Almedina).

GonZÁlez Encinar, J.J. (1990): "Representación y partidos políticos”, en GArrorena Morales, A. (ed.), El Parlamento y sus transformaciones actuales - jornadas organizadas por la Asamblea Regional de Murcia (11-13 de abril de 1988) (Madrid, Tecnos), pp. 75-79.

González Encinar, J.J. (1992): "Democracia de partidos "versus" estado de partidos", en González Encinar, J.J. (coord.), Derecho de Partidos (Madrid, Espasa-Calpe), pp. 17-39.

Grimm, D. (1996): "Los partidos políticos", en Benda, E., et al. Manual de Derecho Constitucional (Madrid, Marcial Pons), pp. 389-444.

Habermas, J. (1961): Mudança estrutural da esfera pública (Rio de Janeiro, Tempo Brasileiro). 
Herrero y Rodríguez de Miñón, M. (2003): "Los partidos como estamentos privilegiados: ideas para su reforma", en AA.VV., La democracia constitucional. Estudios en Homenaje al Prof. Francisco Rubio Llorente (Madrid, CEPC), pp. 201-222.

Holgado González, M. (2006): "Partidos y representación política”, en AA.VV., Derecho Constitucional para el siglo XXI - Actas del VIII Congreso Iberoamericano de Derecho Constitucional (Tomo II, Sevilla, Thompson-Aranzadi) pp. 2691-2701. http://www.goethe.de/in/d/presse/gesetzestexte/s/parteien-erster-s-f.html [fecha de consulta: 19 de septiembre de 2014].

http://www.tse.jus.br/eleicoes/estatisticas/estatisticas-eleitorais-2014-eleitorado [fecha de consulta: 27 de octubre de 2014].

Jiménez CAMPO, J. (1992): "Los partidos políticos en la jurisprudencia constitucional”, en González Encinar, J.J. (coord.), Derecho de Partidos (Madrid, Espasa-Calpe), pp. 201-244.

KeAne, J. (2001): A sociedade civil: velhas imagens e novas visões (Lisboa, Temas e Debates).

Kelsen, H. (1992): Teoria Geral do Direito e do Estado (São Paulo, Martins Fontes). KirChHEIMER, O. (1980): "El camino hacia el partido de todo el mundo", en LENK, K.; Neumann, F., Teoría y sociología críticas de los partidos políticos (Barcelona, Anagrama), pp. 328-347.

La Palombara, J. (2007): "Reflections on political parties and political development, four decades later", en Party Politics (v. 13, No 2), pp. 141-154.

Leibholz, G. (1971): Problemas fundamentales de la democracia moderna (Madrid, Instituto de Estudios Políticos).

Lijphart, A. (1999): Patterns of democracy. Government forms and performance in thirty-six countries (New Haven, Yale University Press).

López Guerra, L. (1977): "El carácter instrumental de las organizaciones partidistas de masa”, en VEGA, P., Teoría y práctica de los partidos políticos (Madrid, Edicusa-Cuadernos para el Diálogo), pp. 101-112.

Lucas Verdú, P. (1984): Curso de Derecho Constitucional. Vol. IV, Constitución española de 1978 y transformación político-social española (Madrid, Tecnos).

Luhmann, N. (1980): Legitimação pelo procedimento (Brasília, UnB).

Luhmann, N. (1983): Sociologia do Direito I (Rio de Janeiro, Tempo Brasileiro). Luhmann, N. (1985): Sociologia do Direito II (Rio de Janeiro, Tempo Brasileiro). MaIr, P. (1997): Party system change: Approaches and interpretations (Oxford, Clarendon Press). 
Marshall, T.H. (1967): Cidadania, classe social e status (Rio de Janeiro, Zahar).

Moraes, A. (2006): Constituição do Brasil interpretada e legislação constitucional (6a ed. São Paulo, Atlas).

MorloK, M. (2000): "La regulación jurídica de los partidos en Alemania", en Teoría y Realidad Constitucional (No 6, 20 semestre). pp. 43-69.

Navarro Méndez, J.I. (1999): Partidos políticos y "democracia interna" (Madrid, CEPC).

NicolaU, J.M. (1997). "As distorçôes na representação dos estados na Câmara dos Deputados brasileira" [fecha de consulta: 12 de septiembre de 2014]. Disponible en: http://www.scielo.br/scielo.php?script=sci_arttext\&pid=S001152581997000300006\&lng=pt\&nrm=iso.

Nogueira Alcalá, M.A. (1994): "Democracia política, gobernabilidad y representación”, em Revista del CLAD Reforma y Democracia (No 1) [fecha de consulta: 6 de julio de 2015]. Disponible en: http://old.clad.org/portal/publicaciones-delclad/revista-clad-reforma-democracia/articulos/001-enero-1994/nogue.pdf.

NoHLEN, D. (2011): La democracia, instituciones, conceptos y contexto (DF, UNAM).

Offe, C. (1988): "Democracia de competencia entre partidos y el estado de bienestar keynesiano: factores de estabilidad y de desorganización”, en OfFe, C., Partidos Politicos y Nuevos Movimientos Sociales (Madrid, Sistema), pp. 55-88.

Panebianco, A. (1982): Modelli di partiti: Organizzazione e potere nei partiti politici (Bologna, Il Mulino).

Pasquino, G. (1985): La complessitá della política (Roma, Laterza).

Presno Linera, M.A. (2000): Los partidos y las distorsiones jurídicas de la democracia (Barcelona, Ariel).

Putnam, R. (1994): Making democracy work (USA, Princeton University Press).

RABAT, M.; CASSIANO, W. (1997): "Distribuição das vagas das unidades federativas da Câmara dos Deputados" [fecha de consulta 19 de septiembre de 2014]. Disponible en: http://www.aslegis.org.br/aslegisoriginal/images/EstudosAcademicos-monografias/representacao_proporcional_na_camara_dos_deputados.pdf.

Ramírez, M. (1980): “Los partidos políticos en la Constitución Española de 1978”, en Revista de Estudios Políticos (nueva época) (No 13, ene./feb.), pp. 45-60.

Reynoso, D. (2002): "Distritos y escaños en Brasil: antecedentes, diagnóstico y consecuencias partidarias del malaporcionamiento" [fecha de consulta: 12 de septiembre de 2014]. Disponible en: http://www.politicaygobierno.cide.edu/ num_anteriores/Vol_VIII_N1_2001/Reynoso.pdf. 
Reynoso, D. (2002): “¿Es tan malo el malapportionment? Sobrerrepresentación distrital, bicameralismo y heterogeneidad", en Republicana Politica y Sociedad (año 1, No 1), pp. 55-64.

Rodríguez DíAz, A. (1989): Transición politica y consolidación constitucional de los partidos politicos (Madrid, Centro de Estudios Constitucionales).

Ryden, D.K. (1996): Representation in crisis-the Constitution, interest groups, and political parties (New York, University of NY Press).

SAISI, K. (2002): "A reforma política e seu impacto no fortalecimento dos partidos políticos: avanço ou retrocesso?" [fecha de consulta: 12 de septiembre de 2014]. Disponible en: http://www.pucsp.br/neamp/artigos/artigo_72.htm.

Sánchez de Vega, A. (1997): "Notas para un estudio del Derecho de Partidos", en Asensi Sabater, J. (coord.), Ciudadanos e instituciones en el constitucionalismo actual (Valencia, Tirant Lo Blanch), pp. 309-326.

SANTOS, B.S. (1991): "Subjectividade, cidadania e emancipação", en Revista Crítica de Ciências Sociais (No 32), pp. 135-191.

SARTORI, G. (1999): Elementos de teoría política. (Madrid, Alianza editorial).

SARTORI, G. (2005): Elementos de teoría política (Madrid, Alianza editorial).

SCHUMPETER, J.A. (1984): Capitalismo, socialismo y democracia (Barcelona, Folio).

SOARES, M.M.; LoURENÇO, L.C. (2004): "A representação política dos estados na federação brasileira" [fecha de consulta: 12 de septiembre de 2014]. Disponible en: http://www.scielo.br/scielo.php?script=sci_arttext\&pid=S010269092004000300008\&lng=pt\&nrm=iso.

Soriano Díaz, R.L. (1999): "El dominio de los partidos políticos: partidos y sociedad", en Revista de Estudios Políticos (nueva época) (No 105, jul./sep.), pp. 265-277.

TAVARES, J.A.G. (1995): “Desigualdades regionais, desigualdades políticas e reforma eleitoral no Brasil", en Indicadores Econômicos (v. 23, No 3).

Teixeira da Mata, J.V. (2001): "Representação parlamentar dos estados" [fecha de consulta: 12 de septiembre de 2014]. Disponible en: http://bd.camara.leg. $\mathrm{br} / \mathrm{bd} /$ bitstream/handle/bdcamara/1483/representacao_parlamentar_mata. pdf? sequence $=1$.

Torres del Moral, A. (1992): Principios de Derecho Constitucional Español 1 (3a ed. renov., Madrid, Servicio de Publicaciones de la Facultad de Derecho).

Ugo Resigno, G. (1995): “Alcune note sulla rappresentanza politica”, en Politica del Diritto (No 4. Anno XXVI), pp. 543-560. 
VAllés, J.M.; Bosch, A. (1997): Sistemas electorales y gobierno representativo (Barcelona, Ariel).

Vega GarCía, P. (1997): "Democracia, representación y partidos políticos (Consideraciones en torno al problema de la legitimidad)", en Asensi Sabater, J. (coord.), Ciudadanos e instituciones en el constitucionalismo actual (Valencia, Tirant lo Blanch), pp. 19-39.

Vega, P. (1977): "Presentación”, en Vega, P. (ed.), Teoria y práctica de los partidos políticos (Madrid, Edicusa-Cuadernos para el Diálogo), pp. 7-26.

Verba, S.; Nie, N.H. (1972): Participation in America-Political democracy and social equality (New York, Harper \& Row Publishers).

Verba, S.; Nie, N.H.; Kim, J.O. (1971): The modes of democratic participation: a cross-national comparison (Beverly Hills, Sage).

Verba, S.; Schlozman, K.L.; Brady, H.E. (1995): Voice and equality. Civic voluntarism in american politics (Cambridge, Harvard University Press).

Ware, A. (1996): Political parties and party systems (Great Britain, Oxford University Press).

Weffort, F. (2009): "Qual reforma política?”, en Estudos Avançados (v. 23, n. 67. Sept.), pp. 38-45.

\section{NORMAS JURÍDICAS CITADAS}

Ley No 4.737, Código Eleitoral, Diário da União do Brasil, 15 de julio de 1965. Constitución de la República Federativa de Brasil. Diário da União, 5 de octubre de 1988.

Ley No 5, Ley Orgánica del Régimen Electoral General, Boletín Oficial del Estado, España, 19 de junio de 1985. 